a. Department of Pediatrics, Hospital Gobernador Centeno, Gral. Pico, Argentina.

b. Division of Clinical Pediatrics, Department of Pediatrics, Hospital Italiano de Buenos Aires, Argentina.

c. Division of Sports, Ministry of Social Welfare, Government of the Province of $\mathrm{La}$ Pampa, Argentina.

d. Fundación

Centro de Salud e Investigaciones Médicas (CESIM), Santa Rosa, Argentina.

e. National Scientific and Technical Research Council (Consejo Nacional de Investigaciones Científicas y Técnicas, CONICET), Argentina.

f. Pediatric Research and Development Institute (Instituto de Desarrollo e Investigaciones Pediátricas [IDIP], Ministry of Health Scientific Research Commission of the Province of Buenos Aires), Hospital de Niños Sor María Ludovica, La Plata, Argentina.

g. School of Exact and Natural Sciences (UNLPam), Santa Rosa, Argentina.

E-mail address:

Javier Fraire, M.D.: javier.fraire@

hospitalitaliano.org.ar

Funding:

This study was

developed thanks to the funding provided by

the Ministry of Social

Welfare of the Province of La Pampa and Universidad Nacional de La Pampa.

Conflict of interest:

None.

Received: 10-23-2020

Accepted: 2-8-2021

\title{
Prevalence of sleep-disordered breathing among adolescents and its association with the presence of obesity and hypertension
}

\author{
Javier A. Fraire, M.D., ${ }^{a, b}$ Noelia M. Deltetto, M.D., ${ }^{a}$ Fabrizio Catalani, B.S., ${ }^{c, d}$ \\ Analisa Beneitez, Student, ${ }^{c, d}$ Lucía Martín, B.S., ${ }^{c, d}$ Daniela Fischman, M.D., ${ }^{c, d}$ \\ Alicia B. Orden, M.D. eff and Marcos Mayer, M.D. ${ }^{d, e, g}$
}

\begin{abstract}
Introduction: The increased prevalence of sleepdisordered breathing (SDB) and its association with obesity and hypertension (HTN) have not been thoroughly explored in adolescents. The objective of this study was to investigate the prevalence of SDB and snoring in this population and analyze its association with obesity and HTN. Population and methods: This was a descriptive, cross-sectional study in a sample of adolescents. Weight, height, waist and neck circumference, and blood pressure were measured, and the Pediatric Sleep Questionnaire (PSQ) was administered.

Results: A total of 826 adolescents participated, $58(7 \%)$ had SDB (males: $5.8 \%$; females: $8 \%$ ), and $80(9.7 \%)$ were considered snorers (males: $10.4 \%$; females: $9.1 \%$ ). Overweight and obesity were detected in $216(26.2 \%)$ and $149(18 \%)$ participants, respectively. A higher proportion of subjects with obesity had SDB compared to those who were not obese $(12.8 \%$ versus $5.8 \%$; $p=0.004)$. The same association was observed with snoring ( $18.2 \%$ versus $7.8 \%$; $p<0.001)$. Also, $24.6 \%$ slept less than 8 hours a day and $12.6 \%$ had values compatible with HTN, with a significant association with obesity and sleep hours.

Conclusion: A high prevalence of SDB and snoring was observed in adolescents, together with an association with obesity and HTN, which highlights the relevance of addressing this problem in an early manner in order to prevent complications.
\end{abstract}

Key words: sleep disorders; snoring; obesity; hypertension; adolescents.

http:/ / dx.doi.org/10.5546/ aap.2021.eng.245

To cite: Fraire JA, Deltetto NM, Catalani F, Beneitez A, et al. Prevalence of sleep-disordered breathing among adolescents and its association with the presence of obesity and hypertension. Arch Argent Pediatr 2021;119(4):245-250

\section{INTRODUCTION}

The term sleep-disordered breathing (SDB) describes a syndrome characterized by variable upper airway obstruction. It encompasses several clinical conditions, from primary snoring to obstructive sleep apnea syndrome (OSAS). It has been estimated that between $1 \%$ and $4 \%$ of the general pediatric population and between $4 \%$ and $11 \%$ of adolescents have SDB. ${ }^{1,2}$

Although it has been considered that SDB in children results from anatomical abnormalities in the upper airways, obesity has been recognized as an important risk factor for the development of this disorder. ${ }^{3}$

Obesity has become a worldwide health problem due to its increased prevalence. Moreover, childhood obesity is an ongoing problem because more than $50 \%$ of children with obesity will be obese adults. ${ }^{4}$

Adolescents with obesity and SDB may show alterations in blood pressure (BP) control and a higher probability of dyslipidemia and insulin resistance, which may be totally or partially reversed with an adequate management. ${ }^{3}$

The objective of this study was to investigate the prevalence of SDB and snoring in adolescents and analyze its association with obesity and hypertension (HTN).

\section{POPULATION AND METHODS}

This was an epidemiological, descriptive, and cross-sectional study. Between August and October 2018, as part of an initiative agreed upon by the Department of Sports and the Ministry of Education of the province 
of La Pampa, a sample made up of children born in 2005 who were attending school in any of the 15 most populous districts in that province was established. Thirty public and private schools that agreed to participate were assessed, which had been randomly selected. Included students accounted for, overall, $15.3 \%$ of the total for the province (as per the National Population Census of 2010, the universe included 5404 students) and represented the different regional realities. The minimum sample size was estimated to assess at least $11 \%$ of the total for the province (represented by at least 594 children), and this percentage was selected due to its feasibility and convenience. All subjects born in 2005 who agreed to participate, whose parents gave their consent and completed the Pediatric Sleep Questionnaire (PSQ) at home, were included. Subjects who did not attend the anthropometric assessment on the expected date were excluded. The study ethical and methodological aspects were assessed and approved by the authorities of the Ministry of Social Welfare and the Ministry of Education. The protocol was approved by the Patagonian Independent Ethics Committee (Comité de Ética Independiente Patagónico, CEIP).

The procedure was performed by the principal investigators, who assessed anthropometric parameters. Participants' parents and/or caregivers completed the sleep questionnaire, which was sent the week prior to the assessment with the corresponding informed consent form, and was returned completed on the day of anthropometric data measurement at school.

Participants' demographic data (sex and date of birth) were obtained from the provincial education system database.

\section{Anthropometric assessment}

Weight was recorded in $\mathrm{kg}$ using a digital scale (Tanita BF $350 ®$ ) with a $10 \mathrm{~g}$ precision and height, in $\mathrm{cm}$ using a portable stadiometer with a $1 \mathrm{~mm}$ precision. Body mass index (BMI) was estimated (weight in $\mathrm{kg} /$ height $^{2}$ in $\mathrm{m}$ ) and used to classify patients into normal weight, overweight, and obese according to the International Obesity Task Force guidelines. ${ }^{5}$ Waist circumference was measured at the umbilical level, at the end of a normal expiration, using a non-extensible tape measure with a $1 \mathrm{~mm}$ precision. Neck circumference was measured both in males and females just below the thyroid cartilage, above the laryngeal prominence, with the subject in standing position and their head adjusted to the Frankfurt plane; the observer was standing in front of the subject or slightly to their side. Abdominal obesity was defined using the waist circumference cut-off points proposed by Fernández et al. based on sex and age, ${ }^{6}$ whereas high neck circumference was defined according to the cut-off points proposed by Souza et al. ${ }^{7}$

\section{BP assessment}

BP was measured two times, after having the subject rest in sitting position for 5 minutes, with a 1-minute interval. The measurement was performed on the right arm, with the subject sitting down with their back against the back of the chair, using a validated digital sphygmomanometer (OMRON model $7121^{\circledR}$ ). In order to identify subjects with high BP values, both BP recordings were averaged. HTN was defined if the systolic $\mathrm{BP}$ was $\geq 130 \mathrm{mmHg}$ and / or diastolic BP was $\geq 80 \mathrm{mmHg}$. ${ }^{8}$

Parents or tutors received the PSQ, aimed at detecting the presence of SDB. Two additional questions were included about sleep hours in order to assess sleep time separately and another questionnaire aimed at assessing physical activity. Sleep hours were estimated based on the time referred by parents about the time their children went to bed and got up in the morning. Compliance with international physical activity guidelines was assessed using a questionnaire validated for the adolescent population, ${ }^{9}$ which allows to estimate compliance or lack of compliance with the recommendation of at least 60 minutes of physical activity a day, and subjects who did not meet this criterion were considered to have a sedentary lifestyle. SDB was assessed with the PSQ, which is made up of 22 items and divided into 3 main domains: snoring (9 items), sleepiness ( 7 items), and inattentive/hyperactive behavior (6 items). An increased risk for SDB was defined if the score was 8 or higher. The questionnaire was validated in Spanish. ${ }^{10}$ For this study, snorer was defined as an adolescent who answered "yes" to at least 1 of the 2 following questions in the PSQ: "Does your child snore more than half the time?" and "Does your child always snore?"

\section{Statistical analysis}

The SPSS software for Windows (version 17.0, SPSS Inc. ${ }^{\circledR}$, Chicago, IL) was used. Data were expressed as mean \pm standard deviation, except when otherwise specified, and analyzed using Student's $t$ test. The association among outcome 
measures was assessed using a $\chi^{2}$ test and Fisher's exact test, or based on logistic regression, as applicable, or univariate or multivariate analyses. A value of $p<0.05$ was considered statistically significant.

\section{RESULTS}

Out of 1017 subjects initially invited to participate in the study, 831 met the inclusion criteria. Of these, 5 were excluded due to an incomplete anthropometric assessment, so the analysis sample was made up of 826 adolescents. Their mean age was $13.12 \pm 0.34$ years. The general characteristics of the sample are shown in Table 1.

TABLE 1. General characteristics of the sample $(N=826)$

\begin{tabular}{lcc}
\hline Outcome measures & $\mathbf{N}$ & $\%$ \\
\hline Sex & & \\
$\quad$ Male & 377 & 45.6 \\
$\quad$ Female & 449 & 54.4 \\
Weight category & & \\
$\quad$ Thinness & 39 & 4.7 \\
$\quad$ Normal weight & 422 & 51.1 \\
Overweight & 216 & 26.2 \\
Obesity & 149 & 18.0 \\
Abdominal obesity & 140 & 16.9 \\
High neck circumference & 146 & 17.7 \\
Hypertension* & 104 & 12.6 \\
\hline
\end{tabular}

*The classification of hypertension is only for epidemiological assessment purposes. The diagnosis of this condition requires an assessment at different time points.
The average number of reported sleep hours was $8.7 \pm 1.4$. There was a tendency towards a higher presence of obesity in subjects who sleep less than 8 hours, although it was not statistically significant (Pearson's $\chi^{2}$ test: 3.334 ; odds ratio: 1.447; $p=0.07)$.

It was observed that 58 out of 826 students (7\%) had values indicative of SDB, and no significant differences were observed between sexes (males: $5.8 \%$ versus females: $8 \%$ ). In turn, $9.7 \%$ of subjects were considered snorers, without differences between sexes (males: $10.4 \%$ versus females: $9.1 \%$ ).

There was a higher prevalence of SDB and snoring among obese students, with an evident and significant association between these conditions. At the same time, both a high waist circumference and a high neck circumference were associated with a higher presence of SDB and snoring (Figures 1 and 2 ).

Table 2 shows the main results of the logistic regression model used to assess the factors associated with the presence of HTN in adolescents. Both obesity and reduced sleep hours have a positive and statistically significant association with the presence of HTN. In turn, there was a positive association between a sedentary lifestyle and HTN, although it was not statistically significant $(p=0.051)$. There was no evidence of a significant relation between sex and $\mathrm{BP}$ or between SDB and HTN.

\section{DISCUSSION}

Few studies in the worldwide and Argentine bibliography have been published about SDB and snoring in adolescents. Based on our data, it was observed that the average reported

FIGURE 1. Association between sleep-disordered breathing and obesity and waist and neck circumference in adolescents $(N=826)$

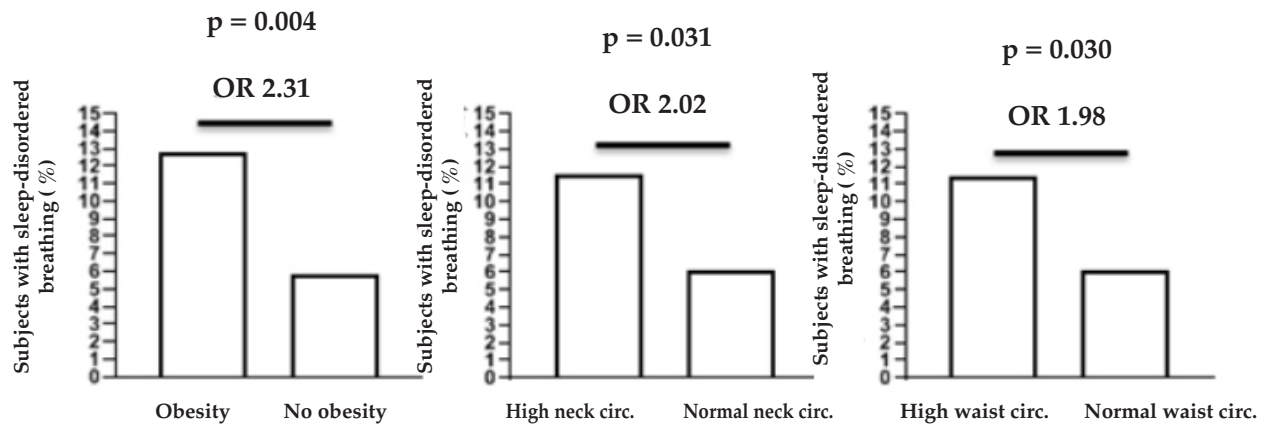


sleep hours was $8.7 \pm 1.4$, and that $24.6 \%$ of assessed subjects did not meet the international recommendations of 8 hours or more of sleep per day. ${ }^{11}$ Also, $7 \%$ of adolescents had SDB. This result is higher than the 0-5.7\% prevalence described in the bibliography. ${ }^{12-14}$ Data of a higher prevalence in adolescents than in children suggest that at least part of the increase of SDB symptoms in adults may start in this stage of life.

There is no universally accepted definition of snoring. In practice, parental perception is the gold standard for diagnosis. ${ }^{15}$ In studies that asked whether snoring occurred always, prevalence was 1.5-6.2 \%; and when asked if it occurred frequently, prevalence was 3.2-14.8\%.15,16 The prevalence of snorers in this sample was $9.7 \%$, consistent with the ranges described in the bibliography.

Among adults, the prevalence of OSAS is affected by obesity. ${ }^{17}$ The controversy of such association persists in children and adolescents. The NANOS study introduced the concept that pediatric obesity is a major risk factor for SDB. ${ }^{18}$ In their studies, Ma et al. and Redline et al. found the same association. ${ }^{19,20}$ This study found a significant association between obesity and SDB. Patients with obesity were more than two times more likely to be snorers or have SDB. A limitation of this observation is that there are no objective data available about adenotonsillar hypertrophy; ${ }^{1,12}$ but it has also been described that, with the reduction of lymphatic tissue due to aging, obesity plays a more relevant role. ${ }^{21,22}$ Phenotypic and etiologic differences in these 2 age groups may explain such findings.

Fat deposits around the airways may cause snoring in the obese population. ${ }^{15}$ In the NANOS study, $50 \%$ of parents reported snoring in a population of obese adolescents, and this value increased to $70 \%$ once a polysomnography was done. ${ }^{18} \mathrm{Ma}$ et al. found a significant association between weight and snoring in adolescents. ${ }^{19}$ Consistent with this evidence, this study found a significant association between obesity and snoring, as snoring was reported by $18.2 \%$ of the

TABLE 2. Results of a logistic regression model to predict hypertension in adolescents based on different factors

\begin{tabular}{lcccc}
\hline Predictors & Beta & Exponencial beta & $\mathbf{9 5 \%}$ CI & $p$ value \\
\hline Male sex & 0,310 & 1,364 & $0,878-2,118$ & 0,167 \\
Sedentary lifestyle & 0,464 & 1,590 & $0,997-2,535$ & 0,051 \\
Sleep hours & $-0,170$ & 0,844 & $0,715-0,995$ & 0,044 \\
Obesity & 1,570 & 4,710 & $3,002-7,389$ & $<0,001$ \\
Sleep-disordered breathing & 0,401 & 1,494 & $0,725-3,080$ & 0,227 \\
\hline
\end{tabular}

CI: confidence interval.
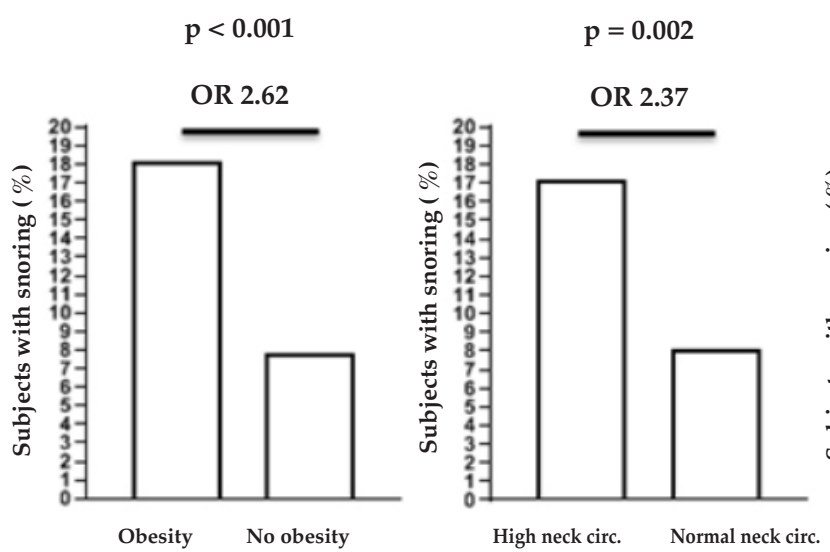

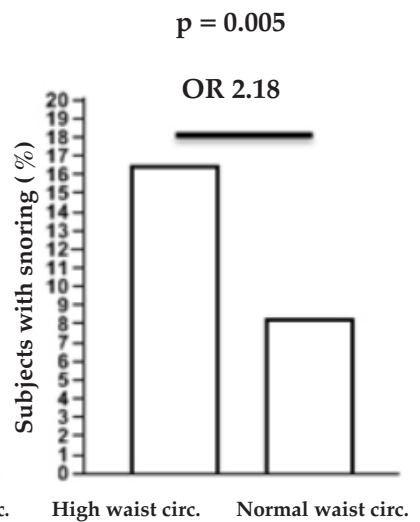


obese population versus only $7.8 \%$ of non-obese subjects.

The increase in neck size in adults is a predictor of OSAS. Glicksman et al. observed that the percentage of neck fat mass in children was associated with the severity of OSAS. ${ }^{23}$ In this study, a significantly higher neck circumference was observed in subjects with SDB and snoring.

In adults, waist circumference is a risk factor for the development of SDB. In adolescents, information is contradictory. Canapari et al. and Danisi et al. demonstrated that waist circumference is associated with an increased risk for SDB in adolescence. ${ }^{24,25}$ On the contrary, Verhulst et al. ${ }^{26}$ reported that SDB was independent from waist circumference. In this study, waist circumference was significantly associated with the presence of SDB and/or snoring.

Risk factors for cardiovascular disease start during childhood and may continue in adulthood. ${ }^{27}$ A systematic review of published studies conducted in children and adolescents in Argentina showed that the prevalence of HTN was $7.35 \%$ and higher in adolescents than in children aged 10 years or younger. ${ }^{28}$ In this study, the prevalence of HTN was $12.6 \%$, which is higher than what has been reported to date. It is important to note that, in 2017, the American Academy of Pediatrics reviewed the definition of HTN, and such definition was adopted by the Sociedad Argentina de Pediatría in 2019; ${ }^{8}$ therefore, the prevalence of prehypertension and/or hypertension in children and adolescents may have changed.

Although multiple factors affect BP in both children and adolescents, there is evidence of the role of obesity in the increased prevalence of HTN in recent decades. ${ }^{29,30}$ This study found a significant association between HTN and obesity.

It has been described that $50 \%$ of adults with resistant HTN develop OSAS. In adolescents, different studies have evidenced that the presence of OSAS may be associated with increased BP. ${ }^{27}$ However, in this study, it was not possible to establish a significant association between HTN and SDB, but this may be due to the lack of statistical power to detect such association in the studied sample.

Sociocultural changes, the increase in school and out-of-school activities, electronic device use, and the culture of a permanent online presence have turned adolescents into a vulnerable population both in relation to the reduction in sleep hours and poor sleep quality. ${ }^{31}$ It has been demonstrated that poor sleep has an effect on the etiopathogenesis of obesity and HTN. ${ }^{32,33}$ This study did not establish an association between sleep hours and obesity. However, a positive association was observed between reduced sleep hours and HTN. This is consistent with a recent meta-analysis, ${ }^{34}$ and highlights the duration of sleep as a factor capable of regulating cardiovascular risk in children and adolescents.

This study has some limitations. The most important limitation is that the PSQ was used to detect the presence of SDB instead of a polysomnography, which is the gold standard procedure. ${ }^{2,35-37}$ Another limitation is that there were no data available about adenotonsillar hypertrophy; therefore, it was not possible to establish a relationship between its presence or absence and snoring and SDB.

Notwithstanding this, it was possible to estimate the prevalence of SDB and snoring in adolescents in Argentina.

\section{CONCLUSIONS}

This study estimated that the prevalence of SDB and snoring in a population of adolescents (mean age: 13 years) was $7.0 \%$ and $9.7 \%$, respectively. SDB and snoring were more prevalent among adolescents with obesity. A reduction in sleep hours and the presence of obesity were significantly associated with higher BP recordings. This study conducted in Argentine adolescents allows to establish the epidemiological factors that may be potentially reversed with an adequate and timely management.

\section{REFERENCES}

1. Kaditis AG, Alonso Alvarez ML, Boudewyns A, Alexopoulos EI, et al. Obstructive sleep disordered breathing in 2- to 18-year-old children: diagnosis and management. Eur Respir J. 2016; 47(1):69-94.

2. SchechterMS. Technical report: Diagnosis and management of childhood obstructive sleep apnea syndrome. Pediatrics. 2002; 109(4):e69.

3. Arens R, Muzumdar H. Childhood obesity and obstructive sleep apnea syndrome. J Appl Physiol (1985). 2010; 108(2):43644.

4. NCD Risk Factor Collaboration (NCD-RisC). Worldwide trends in body-mass index, underweight, overweight, and obesity from 1975 to 2016: A pooled analysis of 2416 population-based measurement studies in 1289 million children, adolescents, and adults. Lancet. 2017; 390(10113):2627-42.

5. Cole TJ, Lobstein T. Extended international (IOTF) body mass index cut-offs for thinness, overweight and obesity. Pediatr Obes. 2012; 7(4):284-94.

6. Fernández JR, Redden DT, Pietrobelli A, Allison DB. Waist 
circumference percentiles in nationally representative samples of African-American, European-American, and Mexican-American children and adolescents. J Pediatr. 2004; 145(4):439-44.

7. Souza MFC, Gurgel RQ, Barreto ÍDC, Shanmugam S. Neck circumference as screening measure for identifying adolescents with overweight and obesity. J Hum Growth Dev. 2016; 26(2):260-6.

8. Sociedad Argentina de Cardiología; Sociedad Argentina de Pediatría. Consenso de prevención cardiovascular en la infancia y la adolescencia. Versión resumida. Recomendaciones. Arch Argent Pediatr. 2019; 117 (Supl 6):S205-42.

9. Laíño F, Balzán N, Santa María C, Salvia A. Validación de un cuestionario de actividad física en niños y adolescentes de Argentina. Apunts Educ Fís Deporte. 2017; 127(1):35-43.

10. Tomás Vila M, Miralles Torres A, Beseler Soto B. Version española del Pediatric Sleep Questionnaire. Un instrumento útil en la investigación de los trastornos del sueño en la infancia. Análisis de su fiabilidad. An Pediatr (Barc). 2007; 66(2):121-8.

11. Paruthi S, Brooks LJ, D'Ambrosio C, Hall W, et al. Recommended Amount of Sleep for Pediatric Populations: A Consensus Statement of the American Academy of Sleep Medicine. J Clin Sleep Med. 2016; 12(6):785-6.

12. Marcus CL, Brooks LJ, Draper KA, GozalD, et al. Diagnosis and management of childhood obstructive sleep apnea syndrome. Pediatrics. 2012; 130(3):e714-55.

13. Johnson EO, Roth T. An epidemiologic study of sleepdisordered breathing symptoms among adolescents. Sleep. 2006; 29(9):1135-42.

14. McArdle N, Ward SV, Bucks RS, Maddison K, et al. The prevalence of common sleep disorders in Young adults: a descriptive population-based study. Sleep. 2020; 43(10):zsaa072.

15. Lumeng JC, Chervin RD. Epidemiology of pediatric obstructive sleep apnea. Proc Am Thorac Soc. 2008; 5(2):24252.

16. Sánchez T, Rojas C, Casals M, Bennett JT, et al. Trastornos respiratorios del sueño en niños escolares chilenos: prevalencia y factores de riesgo. Rev Chil Pediatr. 2018; 89(6):718-25.

17. Newman AB, Foster G, Givelber R, Nieto FJ, et al. Progression and regression of sleep-disordered breathing with changes in weight: the Sleep Heart Health Study. Arch Intern Med. 2005; 165(20):2408-13.

18. Alonso-Alvarez ML, Cordero-Guevara JA, Terán-Santos J, González-Martínez M, et al. Obstructive sleep apnea in obese community-dwelling children: The NANOS study. Sleep. 2014; 37(5):943-9.

19. Ma Y, Peng L, Kou C, Hua S, Yuan H. Associations of Overweight, Obesity and Related Factors with SleepRelated Breathing Disorders and Snoring in Adolescents: A Cross-Sectional Survey. Int J Environ Res Public Health. 2017; 14(2):194.

20. RedlineS, Tishler PV,Schluchter M, Aylor J, et al. Risk factors for sleep-disordered breathing in children: Associations with obesity, race, and respiratory problems. Am J Respir Crit Care Med. 1999; 159(5 Pt 1):1527-32.
21. Chan KC, Au CT, Hui LL, Ng SK, et al. How OSA Evolves From Childhood to Young Adulthood: Natural History From a 10-Year Follow-up Study. Chest. 2019; 156(1):12030.

22. Su MS, Zhang HL, Cai XH, Lin Y, et al. Obesity in children with different risk factors for obstructive sleep apnea: a community-based study. Eur J Pediatr. 2016; 175(2):211-20.

23. Glicksman A, Hadjiyannakis S, Barrowman N, Walker $\mathrm{S}$, et al. Body fat distribution ratios and obstructive sleep apnea severity in youth with obesity. JClin Sleep Med. 2017; 13(4):545-50.

24. Danisi JM, Fernández-Mendoza J, Vgontzas AN, Calhoun SL, et al. Association of visceral adiposity and systemic inflammation with sleep disordered breathing in normal weight, never obese adolescents. Sleep Med. 2020; 69:103-8.

25. Canapari CA, Hoppin AG, Kinane TB, Thomas BJ, et al. Relationship between sleep apnea, fat distribution, and insulin resistance in obese children. J Clin Sleep Med. 2011; $7(3): 268-73$.

26. Verhulst SL, Schrauwen N, Haentjens D, Rooman RP, et al. Sleep-disordered breathing and the metabolic syndrome in overweight and obese children and adolescents. J Pediatr. 2007; 150(6):608-12.

27. Smith DF, Amin RS. OSA and Cardiovascular Risk in Pediatrics. Chest. 2019; 156(2):402-13.

28. Díaz A, Calandra L. Presión arterial elevada en niños y adolescentes escolarizados de Argentina en los últimos 25 años: revisión sistemática de estudios observacionales. Arch Argent Pediatr. 2017; 115(1):5-11.

29. Wühl E. Hypertension in childhood obesity. Acta Paediatr. 2019; 108(1):37-43.

30. Fantin F, Giani A, Zoico E, Rossi AP, et al. Weight loss and hypertension in obese subjects. Nutrients. 2019;11(7):1667.

31. Gariepy G, Danna S, Gobina I, Rasmussen M, et al. How are adolescents sleeping? Adolescent sleep patterns and sociodemographic differences in 24 European and North American countries. J Adolesc Health. 2020; 66(6S):S81-8.

32. Covassin N, Singh P. Sleep duration and cardiovascular disease risk: epidemiologic and experimental evidence. Sleep Med Clin. 2016; 11(1):81-9.

33. Orden AB, Lamarque MS, Chan D, Mayer MA. Short sleep and low milk intake are associated with obesity in a community of school aged children from Argentina. Am J Hum Biol. 2019; 31(3):e23224.

34. Santos ESGD, Souza OF. Evidence of the association between sleep duration and blood pressure in adolescents: a systematic review. Rev Paul Pediatr. 2021; 39:e2019225.

35. KatzSL, Witmans M, Barrowman N, Hoey L, et al. Paediatric sleep resources in Canada: the scope of the problem. Paediatr Child Health. 2014; 19(7):367-72.

36. Chervin RD, Hedger K, Dillon JE, Pituch KJ. Pediatric sleep questionnaire (PSQ): validity and reliability of scales for sleep-disordered breathing, snoring, sleepiness, and behavioral problems. Sleep Med. 2000; 1(1):21-32.

37. Rosen CL, Wang R, Taylor HG, Marcus CL, et al. Utility of symptoms to predict treatment outcomes in obstructive sleep apnea syndrome. Pediatrics. 2015; 135(3):e662-71. 